\title{
A relação entre os conhecimentos presentes na literatura científica e nos livros didáticos de biologia sobre evolução biológica
}

Francisco Paulo Caires Junior

Mariana Aparecida Bologna Soares de Andrade

\section{Resumo}

O objetivo deste trabalho foi analisar conteúdos de livros didáticos relacionados à evolução biológica. A análise foi orientada pelos eixos já consolidados dessa área bem como das discussões atuais que envolvem evodevo, plasticidade e herança epigenética. Foram criadas sete categorias de análise: Contextualização histórica; Darwinismo e Lamarckismo; Síntese Evolutiva Moderna; genética de populações; Biologia do desenvolvimento; Plasticidade; e epigenética. Percebeu-se que os temas de análise das quatro primeiras categorias estão presentes em todos os livros analisados. Mesmo não sendo tratadas como temas da parte de evolução, foram encontradas noções de evo-devo e plasticidade em dois livros. A epigenética não foi encontrada em nenhum dos livros. Essa análise indica que novas pesquisas relacionadas tanto ao ensino de evolução, quanto à inserção de conhecimentos recentemente construídos são necessárias para uma visão mais profunda do tema, e para que se possam propor ações que incrementem o ensino de evolução biológica na educação básica.

Palavras-chave: Ensino de evolução, ensino de biologia, livro didático.

\begin{abstract}
The relationship between the knowledge presented in the scientific literature and in biology textbooks about biological evolution

This study aimed to analyze contents of textbooks related to the biological development. The analysis has been guided by the axis already established in this area as well as the current discussions that involve evodevo, epigenetic and plasticity. Seven categories were created: Historical Context; Darwinism and Lamarckism; Modern Evolutionary Synthesis; Population Genetics; Developmental Biology; Plasticity; and Epigenetics. It was noticed that the themes of the first four categories were present in all studied books. Although these categories have not been treated as part of the themes of evolution, were found notions of evo-devo and plasticity in two books. Epigenetic was not found in any of the books. This analysis indicates that new research related to both the teaching of evolution, as the insertion of newly built knowledge are necessary for a deeper view of the subject and that they may propose actions that enhance biological evolution teaching in primary education.
\end{abstract}




\section{Introdução}

Atualmente, a evolução biológica tem papel central nos estudos das Ciências Biológicas, funcionando como eixo integrador de todos os assuntos da biologia. O processo evolutivo seleciona características adaptativas e essas características estão presentes em todos os níveis organizacionais, seja na morfologia, na fisiologia ou no comportamento dos organismos. Theodosius Dobzhansky, um dos mais importantes biólogos evolucionistas do século XX, considerou que "nada na biologia faz sentido senão à luz da evolução" (DOBZHANSKY, 1973). Futuyma (2002) diz que a teoria da evolução explica os processos que causaram a história dos eventos evolutivos. Segundo o autor, a evolução biológica ocorre como consequência de vários processos fundamentais, que podem ser tanto aleatórios quanto não-aleatórios:

"A variação nas características dos organismos de uma população surge por meio de mutação aleatória de sequências de DNA (genes) que afetam aquelas características. Aqui, "aleatório" significa que as mutações ocorrem sem levar em conta suas possíveis consequências na sobrevivência ou na reprodução. [...] A variação genética é aumentada pela recombinação durante a reprodução sexuada, que resulta em novas combinações dos genes. A variação também é aumentada pelo fluxo gênico, o aporte de novos genes de outras populações" (FUTUYMA, 2002, P. 9).

Ainda de acordo com Futuyma (2002, p.10), os fatores que fazem diminuir a diversidade genética nas populações e fixar determinados alelos são, primeiramente, a seleção natural, que segundo o autor representa "qualquer diferença consistente (não aleatória) entre organismos portadores de alelos ou genótipos diferentes quanto à sua taxa de sobrevivência ou reprodução". Segundo ele, na maioria dos casos há fatores ambientais que determinam quais variações terão mais valor adaptativo, mas muitas vezes as interações que o organismo estabelece com membros da mesma espécie, e de outras espécies também, são importantes. Além disso, a deriva genética também é um fator essencial, que resulta da variação aleatória da sobrevivência e da reprodução de genótipos diferentes. A mudança evolutiva, portanto, resulta na mudança das proporções dos alelos na população. (FUTUYMA, 2002, p. 10). Considerando esse fato, entende-se a importância que o ensino de evolução tem para o ensino médio. É através do entendimento de que uma das características mais marcantes da vida em nosso planeta é a evolução, e dos mecanismos do processo evolutivo, que os estudantes do nível médio conseguirão adquirir uma visão sistêmica da biologia.

Um importante aliado no processo de aprendizagem é o livro didático (LD). Seguido - por vezes, demasiadamente - pelos professores, o LD é muitas vezes a única ferramenta de apoio

DOI: Em andamento. 
disponível na escola. Segundo os Parâmetros Curriculares Nacionais (PCNs), a evolução deve ser ensinada junto com outros conteúdos de biologia, de maneira integrada e unificadora (BRASIL, 2006 , p. 22). Independentemente de seguirem essa orientação, os LD trazem um capítulo, ou capítulos, tratando especificamente desse tema, com a contextualização histórica do processo de elaboração dos conhecimentos evolutivos e os mecanismos pelos quais as espécies evoluem. Esse conteúdo geralmente é posicionado no final da obra e o "tema evolução" costuma ser um dos últimos assuntos a ser trabalhado, no fim do ensino médio (TIDON, LEWONTIN, 2004). Desta maneira, a evolução não é usada para atribuir sentido aos seus produtos, tal como a diversidade biológica. É frequentemente ensinada como um desfile de diferentes táxons, sem qualquer processo subjacente que os reúna (ROCHA et al., 2007 apud BIZZO \& EL-HANI, 2007).

Uma discussão atual refere-se aos conteúdos da biologia que estão essencialmente envolvidos na evolução biológica. A síntese evolutiva moderna, ocorrida entre as décadas de 1930 e 1940, conciliou a ideia darwiniana de seleção natural aos princípios mendelianos de herança, e provou que os dois fenômenos atuam juntos no processo evolutivo. É fato que de lá para cá a área das ciências biológicas teve uma expansão notória. Além dos avanços na genética molecular outros campos surgiram ao longo desse tempo. É o caso da genômica e da biologia evolutiva do desenvolvimento, comumente chamada de evo-devo. Assim, pesquisadores esforçam-se para que esses novos conhecimentos possam tornar ainda mais completo o entendimento de como os organismos vivos evoluem (PIGLIUCCI, 2009).

Desse modo, pretendemos com esse trabalho a realização um levantamento das principais áreas do conhecimento que auxiliam na construção dos conhecimentos sobre os processos evolutivos; e uma análise, a partir da revisão elaborada, de como livros didáticos apresentam os conteúdos referentes à evolução biológica.

\section{0 ensino de evolução}

Para Ridley (2006), a teoria da evolução é a mais importante das teorias biológicas. Segundo o autor:

\footnotetext{
"Em biologia, nenhuma outra ideia é tão poderosa cientificamente ou tão estimulante do ponto de vista intelectual. A evolução pode acrescentar uma dimensão extra de interesse às faces mais atraentes da história natural [...]. A evolução também empresta significado aos fatos mais áridos da vida [....]" (RIDLEY, 2006, p. 5).
}

Os cientistas costumam dizer que a biologia evolutiva é o eixo transversal que percorre todas as áreas das ciências biológicas, atingindo inclusive alguns segmentos das ciências exatas e das ciências humanas. Segundo Tidon e Vieira (2009), a teoria da evolução, acrescida das atualizações e desdobramentos ocorridos nos últimos 150 anos, não só explica a diversidade da

62 DOI: Em andamento. R. Bras. de Ensino de C\&T 
vida como também proporciona uma excelente oportunidade para análises e reflexões que desenvolvem o espírito crítico daqueles que a estudam. Por isso, ponderam os autores: "por essas razões, o ensino dessa disciplina contribui para formar uma cidadania informada, capaz de tomar decisões pensadas e de se adaptar a mudanças [...]" (TIDON; VIEIRA, 2009).

As pesquisas na área da biologia evolutiva criaram conceitos e aperfeiçoaram técnicas que permitiram entender com mais clareza a diversidade da vida, representada pela variabilidade genética. $O$ estudo da evolução biológica ajuda a entender, por exemplo, porque existem doenças desencadeadas por defeitos genéticos e calcular a probabilidade de filhos de casais herdarem esse tipo de doença: "o aconselhamento genético é Genética de Populações aplicada, pois, para calcular a probabilidade de se herdar um defeito genético, baseia-se tanto na análise genealógica (genética padrão) como no conhecimento da frequência de um determinado alelo na população" (FUTUYMA, 2002, p. 20).

Para expressar a importância da evolução biológica, Carroll (2006) faz uma analogia da biologia com a física:

"A biologia sem a evolução é como a física sem a gravidade: assim como não podemos explicar a estrutura do Universo, as órbitas dos planetas e da Lua ou as marés por meio de simples medições, tampouco podemos compreender a biologia humana ou a diversidade na Terra a partir de um compêndio de fatos menores. Todos os cursos ou textos introdutórios devem adotar a evolução como seu tema unificador central" (CARROLL, 2006. P. 259).

Ernst Mayr, expoente biólogo evolucionista do século XX e divulgador do conhecimento biológico, escreveu:

"Existem ainda, obviamente, numerosos enigmas por solucionar, como a função de todo o DNA não codificante, mas não consigo ver em que a resolução de qualquer um dos enigmas restantes possa ter um efeito perceptível no paradigma darwiniano básico" (MAYR, 2005, p. 146).

Alguns autores como Dobzhansky, Futuyma e Gould destacam a evolução como elemento unificador dos conhecimentos de toda a Biologia (GOEDERT, 2004 apud DALAPICOLLA et al., 2011). Com relação a evolução como conteúdo da educação básica, temos que o ensino de evolução no Brasil é componente curricular do terceiro ano do ensino médio, mas é importante assinalar que esse tema deve ser enfocado dentro de outros conteúdos, como a diversidade biológica ou o estudo da classificação dos seres vivos, por exemplo. A presença da biologia evolutiva junto com diferentes outros conteúdos não representa a diluição do tema evolução, mas sim a sua articulação com outros assuntos, como elemento central e unificador no estudo da Biologia. (BRASIL, 2006, p. 22). A biologia e os conceitos biológicos estão presentes no dia-a-dia das pessoas, mas, contraditoriamente, o ensino dessa disciplina encontra-se tão distanciado da realidade que não

DOI: Em andamento. 
permite aos alunos perceber o vínculo estreito existente entre o que é estudado na disciplina Biologia e o cotidiano. "Essa visão dicotômica impossibilita ao aluno estabelecer relações entre a produção científica e o seu contexto, prejudicando a necessária visão holística que deve pautar o aprendizado sobre a Biologia" (BRASIL, 2006, p. 19).

Um estudo feito por Goedert e colaboradores (2003) destaca que vários trabalhos têm tratado da problemática do ensino de evolução no país. Esse estudo aponta que equívocos são cometidos, e que os fatores para que isso aconteça, são diversos: posicionamentos próprios dos professores, concepções prévias dos alunos e de entendimentos equivocados, possivelmente decorrentes de dificuldades não resolvidas na formação inicial dos docentes (GOEDERT, DELIZOICOV; ROSA, 2003). Dificuldades são apontadas também por Tidon e Vieira (2009), na pesquisa realizada por esses pesquisadores, entre os obstáculos encontrados figuram problemas com o material didático, currículo e concepções erradas dos professores.

Goedert e colaboradores (2003) ainda consideram que por a evolução biológica "ser um princípio gerador de controvérsias e por deter um caráter fundamental no conhecimento biológico", requer que os professores tenham uma boa formação inicial, de maneira clara e objetiva, para evitar possíveis erros conceituais e concepções distorcidas. Segundo eles, é evidente que muitos professores se sentem despreparados para trabalhar o tema da evolução em sala de aula e que isso ocorre porque durante a formação inicial, os conhecimentos evolutivos não são compreendidos a contento, ou não são trabalhados de maneira integrada com outras áreas da biologia. Essa falta de articulação durante a graduação acaba sendo refletida na ação pedagógica do professor, que tem dificuldades de abordar o assunto ao longo da disciplina, relacionando-o com outros temas. Outro ponto destacado é o fato de que os professores sentem a necessidade de atualização. Essa, no entanto, por vários motivos, nem sempre acontece (GOEDERT; DELIZOICOV; ROSA, 2003).

Esse trabalho ressalta ainda que o conflito religioso diante do tema evolução é outro problema difícil de enfrentar uma vez que os alunos nem sempre estão prontos para entender os mecanismos evolutivos e/ou conciliá-los com suas concepções religiosas (GOEDERT; DELIZOICOV; ROSA, 2003). Quanto ao tema, Rosa (2002) salienta que conceber a evolução sob uma ótica religiosa é uma questão presente não apenas nas concepções dos alunos, mas também nas dos professores (ROSA et al., 2002 apud GOEDERT et al., 2003). Tidon e Vieira (2009) afirmam que embora nosso país não apresente fortes tradições criacionistas, nos últimos anos foram sugeridas propostas educacionais de caráter não-científico como a contratação de professores de religião para ensinar sobre a origem e diversificação da vida, e a sugestão equivocada de que a teoria do "planejamento inteligente" (intelligent design) é científica. Na visão dos autores, se essas propostas forem adotadas podem comprometer irremediavelmente a qualidade do ensino de ciências e biologia. Segundo os mesmos, no final de 2008 o Ministério da Educação (MEC) reforçou sua posição no debate relativo ao ensino do criacionismo nas escolas do país: "esse modelo não deve ser 
apresentado em aulas de ciências, como fazem alguns colégios privados, em geral confessionais" (TIDON \& VIEIRA, 2009).

Bizzo \& Pellegrini (2013) apontam que pesquisas centradas na temática de ensinoaprendizagem e concepções da teoria da evolução biológica começaram a ser desenvolvidas no início da década de 1990. Inicialmente o foco das pesquisas eram os elementos do ensino e prática do professor, todavia ultimamente as pesquisas têm se preocupado com as concepções prévias e representações de professores e alunos. Segundo os autores: "a aprendizagem passa a ser entendida como um processo ativo" (BIZZO \& PELLEGRINI, 2013, p. 93). Os mesmos autores pontuam ainda que há "um número reduzido de trabalhos voltados especificamente à aprendizagem do tema junto a alunos do ensino médio" (BIZZO \& PELLEGRINI, 2013, p. 95).

\section{O conteúdo de evolução nos livros didáticos}

Os Parâmetros Curriculares Nacionais recomendam que todas as ciências biológicas sejam conectadas transversalmente por um eixo ecológico-evolutivo. Para Tidon e Vieira (2009), o Programa Nacional do Livro Didático têm proporcionado uma melhoria significativa na qualidade dessas obras, aprimorando a correção conceitual e metodológica em várias disciplinas, inclusive a evolução biológica (TIDON; VIEIRA, 2009). De uma maneira geral, os LD fazem com que o conceito evolutivo permeie, em maior ou menor grau, os assuntos abordados durante a disciplina. É comum, no entanto, que os livros reservem um momento da disciplina, trazendo um capítulo - ou alguns capítulos - para abordar a evolução especificamente. Nesse espaço, é feito uma contextualização histórica, por vezes mais rica em detalhes e fatos, outra vezes com o apontamento dos principais eventos referentes à construção do conhecimento evolutivo.

Seguindo essa tendência, os professores acabam deixando o conteúdo de evolução para o fim do ensino médio, geralmente nos últimos meses do último ano. Bizzo \& El-Hani (2009) pontuam que "se deixarmos a evolução para o fim da educação básica, ela tenderá a ser abordada de modo impróprio e não cumprirá o papel integrador que efetivamente tem no conhecimento biológico".

Segundo Tidon e Vieira (2009) três ações necessárias para a melhora do ensino de evolução são: o contínuo aperfeiçoamento dos LD, aperfeiçoamento e a atualização do currículo, e por fim, a formação e atualização dos professores de biologia, já que alguns ainda possuem visões lamarckistas da evolução. Cursos de aprimoramento podem ajudar o professor a identificar suas pré-concepções, a mudança conceitual necessária, e a atualização dos conhecimentos. A metodologia de superação dos seus conhecimentos prévios, que trazem uma visão distorcida dos processos evolutivos, pode ajudá-los no momento de orientar os alunos pelo mesmo caminho, fazendo com que estes além de incorporarem a visão evolutiva, desenvolvam um pensamento crítico. 
Com o objetivo de discutir a relação entre o conhecimento científico e o que é apresentado nos LD, o próximo item apresenta discussões científicas atuais sobre a evolução biológica.

\section{O cenário da produção científica sobre evolução biológica}

Ao analisar os acontecimentos que levaram a concretização do pensamento evolutivo corrente hoje, percebe-se que a ideia de evolução biológica passou por marcos históricos importantes. Segundo Ridley (2006), quando Darwin divulgou suas ideias sobre a evolução, e explicou o efeito e o modo de ação da seleção natural, ele não tinha uma explicação satisfatória para a herança das características. Por isso, a importância da seleção natural foi muito questionada na época. A respeito da obra de Darwin, Mayr (2005) escreve:

"A obra de Darwin como um todo é o fundamento de uma nova filosofia da biologia, que se desenvolve rapidamente. Não pode haver dúvida de que a maneira de pensar de toda pessoa ocidental moderna foi profundamente afetada pelo pensamento filosófico de Darwin" (MAYR, 2005, p. 112).

Ainda sobre a importância das proposições de Darwin acerca de a evolução biológica, Mayr (2005) completa:

"O período que vai dos anos 1940 (síntese evolucionista) até o presente tem sido de grandes avanços em biologia, incluindo o surgimento $e$ a ascensão espetacular da biologia molecular. Seria de esperar que isso tivesse ocasionado uma revisão cabal do darwinismo. Contrariamente à expectativa, nada do gênero aconteceu. O paradigma darwiniano produzido nos anos 1940, durante a síntese evolucionista, foi capaz de resistir sem uma revisão significativa nos últimos cinquenta anos" (MAYR, 2005, p. 145).

Nas décadas de 1920 e 1930, no entanto, foi demonstrado que a seleção natural podia operar em conjunto com os princípios mendelianos. Nesse período, os princípios básicos da herança biológica já estavam bem esclarecidos e aceitos. A inovação consistiu em conciliá-los com a ideia de seleção natural proposta por Darwin 60 anos antes. Futuyma (2009) explica as conquistas dos pesquisadores empenhados nesse desafio, entre eles Ronald A. Fisher (1890 - 1962), John B. S. Haldane (1892 - 1964), Sewall Wright (1889 - 1988), Theodosius Dobzhanski (1900 - 1975), Ernst Mayr (1904 - 2005) e Julian Huxley (1887 - 1975):

"As maiores realizações desses e de outros cientistas foram integrar totalmente genética e a teoria evolutiva darwiniana e argumentar persuasivamente (pelo menos, muitas pessoas foram persuadidas) de que mutação, recombinação, seleção natural, e outros processos que operam dentro das espécies justificam as características principais e de longo prazo da evolução lo que Dobzhansky nomeou 'macroevolução)" (FUTUYMA, 2009, p. 25). 
Sobre a importância da Síntese Moderna e a contribuição dos pesquisadores envolvidos na concretização desta, Pigliucci (2009) pontua:

"A resolução deste impasse começou com o trabalho clássico de Fisher (1918), Wright (1932), e Haldane (1932), que estabeleceu as bases do campo da genética estatística populacional. Estes autores mostraram elegantemente que as expressões em comum de vários genes Mendelianos discretos podem cumulativamente produzir o efeito de uma distribuição contínua, Gaussiana de fenótipos. Não só não houve contradição entre Darwinismo e Mendelismo, mas na verdade o último forneceu a teoria muito procurada da hereditariedade que tinha iludido Darwin e seus contemporâneos. Esta reconciliação interdisciplinar , no entanto, foi apenas o início da MS (moderna síntese), que foi submetida a uma segunda e expansiva fase durante os anos 1930 e 1940. O trabalho adicional tomou a forma de uma série impressionante de livros por Dobzhansky (1937), Huxley (1942), Mayr (1942), Simpson (1944), e Stebbins (1950). O corpo resultante da teoria realmente merece a denominação de "síntese" na medida em que teceu junto não só neo-darwinismo e genética populacional, mas também zoologia, botânica, paleontologia e história natura" (PIGLIUCCI, 2009, p. 220).

Contudo, Pigliucci (2009) defende ainda que se faz necessário uma discussão sobre a necessidade de uma possível atualização do quadro conceitual da moderna síntese da evolução. De acordo com o autor, áreas que surgiram mais recentemente como a genômica e a biologia evolutiva do desenvolvimento, conhecida como evo-devo, têm um conjunto de novos conhecimentos, que não estavam disponíveis quando da síntese moderna. Sob à luz desse panorama, Pigliucci (2009) propõe a integração de outras áreas da biologia para o entendimento da evolução biológica e, segundo ele, conceitos importantes, que podem ampliar o conhecimento sobre os processos evolutivos são: a teoria de construção de nichos, na área de ecologia; o papel do desenvolvimento e evolução das formas dos organismos; a epigenética, estudos genômicos, uma extensão da seleção natural com a teoria de seleção em multi-níveis (multilevel selection theory); modularidade (modularity) e evohabilidade (evolvability) e formas alternativas de herança. Por fim, as propriedades emergentes dos sistemas biológicos, que fornecem um mecanismo adicional de geração de potencial adaptativo em fenótipos complexos (PIGLIUCCI, 2009). Ademais, esses são temas relacionados e que tem despertado a atenção de muitos pesquisadores atualmente.

Para explicar a atualização que defende, Pigliucci (2009) apresenta a seguinte figura: 


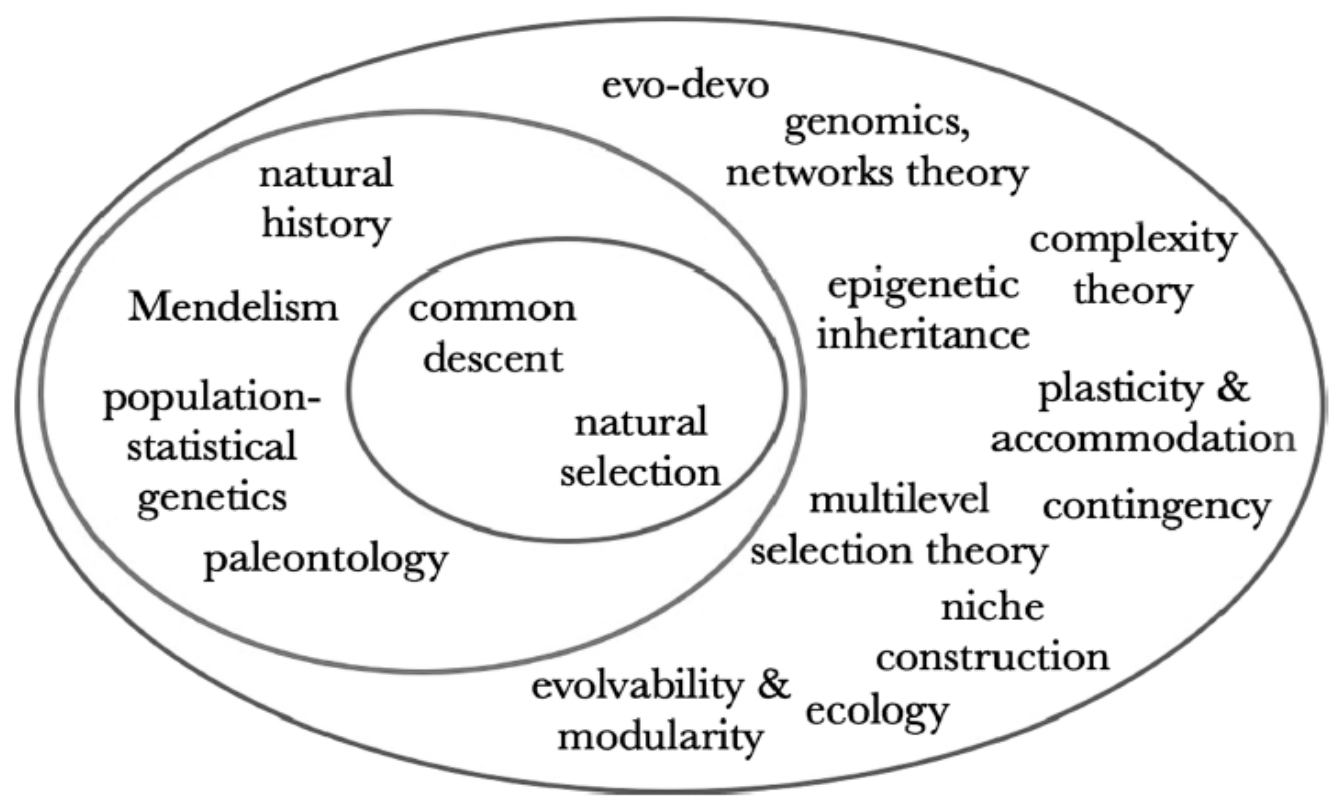

Figure 1. Conceptual representation of the continuous expansion of evolutionary theory in terms of ideas, phenomena studied, and fields of inquiry. The smallest ellipse represents the original Darwinism, the intermediate ellipse is the MS, and the largest ellipse stands for the ES.

Figura 1 - Quadro de atualização conceitual, proposto por Pigliucci (2009).

Segundo o autor, a figura descreve os conhecimentos relacionados à evolução biológica, em três diferentes níveis. Na elipse mais interna, está o cerne da teoria evolutiva, representado pelas proposições de Darwin de ancestralidade comum e seleção natural. A Moderna Síntese Evolutiva, representada pela segunda elipse, que engloba o darwinismo clássico, acrescenta ao pensamento evolutivo os conhecimentos de história natural, paleontologia, genética populacional, além dos princípios mendelianos de herança biológica. Por fim, a elipse mais abrangente, traz as áreas do conhecimento que, segundo Pigliucci (2009), podem contribuir atualmente para o entendimento mais amplo e completo do processo de evolução biológica. A biologia do desenvolvimento (evo-devo), genômica, teoria de redes, teoria da complexidade, herança epigenética, plasticidade, acomodação, contingência, teoria da seleção em muitiníveis, construção de nichos, modularidade (modularity), evohabilidade (evolvability) e ecologia são, segundo o autor, os conhecimentos recentemente desenvolvidos e relacionados à evolução biológica.

Vale ressaltar que, segundo esta proposição, todos os conhecimentos mencionados e os três diferentes níveis de abrangência (representados pelo darwinismo clássico, síntese moderna e novos conhecimentos) são complementares e inclusivos. Assim, quando se pensa em áreas recentes do conhecimento ajudando a explicar o processo evolutivo, não se descarta a contribuição e os princípios propostos por Darwin, tampouco aqueles da Moderna Síntese Evolutiva.

Entre os conhecimentos referidos por Pigliucci (2009) como provenientes de novas áreas do conhecimento científico e que ajudam no entendimento da evolução biológica, escolhemos três temas para o foco de análise deste trabalho. Foram escolhidos os temas biologia do 
desenvolvimento (evo-devo), plasticidade e epigenética. A escolha aconteceu de modo empírico, por acreditarmos que dentro do rol de conhecimentos discutidos pelo autor, esses são os mais intimamente relacionados com as ciências biológicas e também, aqueles que têm maior possibilidade de aparecer dos LD.

O primeiro tema escolhido é a biologia do desenvolvimento, muitas vezes referida como evo-devo. Segundo Futuyma (2009),

"[...] o campo da biologia evolutiva e do desenvolvimento busca compreender os mecanismos pelos quais o desenvolvimento evoluiu, tanto em termos dos processos de desenvolvimento (por exemplo, qual novidade na interação entre células ou tecidos é responsável pelas novidades morfológicas em certos taxa) e em termos de processos evolutivos (por exemplo, quais pressões seletivas promovem a evolução dessas novidades morfológicas". (FUTUYMA, 2009b, $p$. 554, tradução nossa).

Carroll (2006) resume a importância e o objeto de estudo da biologia do desenvolvimento:

"O desenvolvimento está intimamente relacionado à evolução, porque a diversidade morfológica surge por meio de alterações nos embriões. [...] A embriogênese é a transformação de um óvulo fecundado em um embrião em crescimento e, por fim, sua forma adulta. A evolução da forma ocorre por meio de alterações do desenvolvimento embrionário" (CARROLL, 2006, p. 8 e 13).

Para o autor "a evo-devo pode contribuir com muitos conhecimentos novos, concretos e convincentes" (CARROLL, 2006. P. 259).

Outro tema escolhido é a plasticidade ou plasticidade fenotípica adaptativa, que é a capacidade de um genótipo produzir diferentes resultados fenotípicos, dependendo das condições ambientais. Segundo Futuyma (2009):

"Algumas características podem exibir plasticidade fenotípica adaptativa, a capacidade de um genótipo expressar diferentes fenótipos em diferentes condições ambientais. (A variedade particular de fenótipos expressada é a norma de reação). A plasticidade fenotípica tem dois padrões principais (não completamente distintos). Mudanças reversíveis em geral são adaptações a flutuações ambientais bastante previsiveis com um período longo, que o organismo provavelmente experimenta durante sua vida. Exemplos claros são as mudanças sazonais na plumagem de muitos pássaros e na pelagem de alguns mamíferos em regiões temperadas e polares. Diferenças menos prováveis, ou irreversíveis, que frequentemente se iniciam nos primeiros estágios do desenvolvimento, são prováveis caso o organismo tenha a chance de ser exposto a apenas um ou outro estágio do fator ambiental durante sua vida. Por exemplo,

R. B. E. C. T., vol 8, núm. 3, mai-ago.2015 ISSN - 1982-873X

DOI: Em andamento. 
a forma da folha de algumas plantas semi-aquáticas depende do fato de a folha ter se desenvolvido abaixo ou sobre a água. [...] Tais diferenças irreversíveis 'tudo-ou-nada' são chamadas frequentemente de interruptores desenvolvimentais" (FUTUYMA, 2009 p. 70).

Em outro momento, o autor considera importante diferenciar a plasticidade fenotípica dos efeitos que podem ser causados por alelos alternativos dos genes. Ressalta:

\begin{abstract}
"Note que aqui não estamos nos referindo ao polimorfismo genético - genótipos diferentes adaptados à diferentes condições - mas sim à evolução de um genótipo capaz de alterar adaptativamente o desenvolvimento ou a expressão de uma característica adaptada para se adequar às condições que os organismos individuais encontram . Muitas vezes, essa capacidade é chamada de plasticidade fenotípica" (FUTUYMA, 2006. P. 439).
\end{abstract}

O terceiro tema escolhido para essa revisão são os fatores de herança epigenética. Esse fenômeno está relacionado com a herança de fatores sem que haja alteração da sua sequência nucleotídica, "a herança epigenética descreve a habilidade de diferentes estados, que deve ter diferentes consequências fenotípicas, que podem ser herdados sem nenhuma mudança na sequencia do DNA" (LEWIN, 2009, P. 819, tradução nossa). O autor explica que esse tipo de herança pode ocorrer: por metilação de uma base; uma estrutura proteica que se liga ao DNA, ou uma proteína agregada (por exemplo, um príon) que "sequestra" uma proteína impossibilitando seu funcionamento normal.

Em relação à epigenética, Muller (2010) salienta:

"A teoria da inovação epigenética argumenta que a variação genética, seleção natural, e indução ambiental afetam sistemas de desenvolvimento integrados que geram específicas reações fenotípicas quando a plasticidade canalizada atinge um limite" (MULLER, 2010. P. 322).

A evolução é sempre referida como um processo complexo e multifatorial. Desse modo, é importante para o aprendizado a compreensão de que existem outros fatores além da sempre citada seleção natural, e que o processo evolutivo não atua independentemente de outras forças biológicas como os fenômenos moleculares e ecológicos. Em virtude de a evolução biológica configurar-se por um conjunto de processos e fenômenos que resultam na mudança de populações; e diante das atuais discussões conceituais, escolhemos os temas de biologia evolutiva do desenvolvimento, epigenética e plasticidade como foco de análise deste trabalho. Consideramos que esses conteúdos podem proporcionar ao aluno uma gama maior de conhecimentos que contribuem para o entendimento mais amplo da evolução biológica. 


\section{Metodologia da pesquisa}

Esse trabalho caracterizou-se como uma pesquisa qualitativa. Segundo Bogdan e Biklen (2006), a pesquisa qualitativa tem sempre algumas características, entre elas, o fato de ser uma investigação descritiva, na qual muitas vezes o processo é mais ou tão importante quanto os resultados e a análise dos dados é feita de forma indutiva. Além disso, o investigador compõe-se como instrumento principal (BOGDAN; BIKLEN, 2006, p. 48).

Nesse sentido, após o levantamento sobre os conteúdos de evolução na literatura, organizou-se a coleta de dados. Foram analisados seis livros didáticos que são usados por professores nas escolas públicas e privadas da região de Londrina, Paraná. Os livros escolhidos foram:

LD1: AMABIS, J. M. MARTHO, G. R. Biologia: volume 3 - biologia das populações. 3 ed. São Paulo: Moderna, 2010. v. 3. Cap. 6 a 8, p. $145-227$.

LD2: LINHARES, S. GEWANDSZNAJDER, F. Biologia. São Paulo: Ática, 2010. v. único. Cap. 44 e 45, p. $420-450$.

LD3: LOPES, S. ROSSO, S. Bio: volume 2. São Paulo: Saraiva, 2010. v. 2. Cap. 12 e 13, p. $430-478$.

LD4: MENDONÇA, V. LAURENCE, J. Biologia: o ser humano, genética, evolução. São Paulo: Nova Geração, 2010. v. 3. Cap. 11 e 12, p. 212 - 257.

LD5: PAULINO, W. R. Biologia volume 3: genética, evolução, ecologia. São Paulo: Ática, 2005. v. 3. Cap. 10 a 12, p. $129-164$.

LD6: SILVA JUNIOR, C. SASSON, S. CALDINI JUNIOR, N. Biologia 3: genética, evolução, ecologia. 9 ed. São Paulo: Saraiva, 2010. v. 3. Cap. 15 a 20, p. $201-259.22$

Em uma metodologia de pesquisa qualitativa, os dados caracterizam-se como palavras ou imagens, e:

"[...] os resultados escritos da investigação contém citações feitas com base nos dados para ilustrar e substanciar a apresentação. Os dados incluem transcrições de entrevistas, notas de campo, fotografias, vídeos, documentos pessoais, memorandos e outros registros oficiais" (BOGDAN, BIKLEN, 2006, p. 48).

Para uma melhor visualização da análise e comparação mais eficiente entre as obras, trechos dos LD foram transcritos e organizados em categorias iniciais. Ao longo do processo de análise essas categorias foram reelaboradas. A tabela de análise (tabela 1), que indica a presença ou ausência do conteúdo pesquisado em cada categoria é apresentada nos resultados.

De acordo com a análise de conteúdo proposto por Bardin, embora não seja uma etapa obrigatória, a maioria das análises envolve a categorização. Segundo a autora:

R. B. E. C. T., vol 8, núm. 3, mai-ago.2015 ISSN - 1982-873X

DOI: Em andamento. 


\begin{abstract}
"A categorização é uma operação de classificação de elementos constitutivos de um conjunto, por diferenciação e, seguidamente, por reagrupamento segundo o gênero (analogia), com os critérios previamente definidos. As categorias são rubricas ou classes, as quais reúnem um grupo de elementos (unidades de registro, no caso da análise de conteúdo) sob um título genérico, agrupamento esse efetuado em razão dos caracteres comuns destes elementos" (BARDIN, 1977, p. 117).
\end{abstract}

Para a análise, foram criadas sete categorias. Dessa maneira, o conteúdo de evolução pode ser classificado segundo níveis de abrangência do conhecimento e conceitos dentro da teoria evolutiva. As categorias são:

\title{
Categoria 1: Contextualização histórica.
}

Nesta categoria analisou-se o conteúdo do texto referente à descrição histórica dos fatos e eventos relacionados ao conhecimento evolutivo. Atentou-se, também, para a visão que os autores imprimem sobre a construção do conhecimento científico. Buscou-se diferenciar as obras que trazem simplesmente a cronologia de eventos como nascimento e falecimento de pesquisadores ou ano da publicação de livros e aquelas que apresentam uma discussão sobre o momento histórico, as influências e fatores envolvidos na mudança conceitual do pensamento evolutivo nos últimos dois séculos e meio.

\section{Categoria 2: Lamarckismo e Darwinismo.}

O foco aqui foi a maneira como as teorias de Lamarck e Darwin são expostas. Identificouse também a importância relativa que os escritores atribuem a cada um, sobretudo à Lamarck. Isso porque é comum que, no ensino médio, esse pesquisador seja visto como tolo ou ingênuo e que suas ideias sejam consideradas todas erradas.

\section{Categoria 3: Síntese Evolutiva Moderna.}

Identificaram-se referências e explicações do movimento de síntese evolutiva ocorrido no início do século XX. Sempre que possível foi observado se os autores trazem Neodarwinismo como sinônimo de Síntese Evolutiva Moderna.

\section{Categoria 4: Genética de populações.}

Nesta categoria procurou-se a presença da genética de populações nas obras e como é feita a explicação do teorema de Hardy-Weinberg. Outro ponto significativo pesquisado foi a maneira pela qual os autores justificam a importância desse conhecimento e como mostram a articulação e aplicação da genética e da explicação estatística (modelo matemático) no processo evolutivo. 
Para as categorias 5, 6 e 7 buscou-se no texto todo que trata de evolução, referências ou indícios que pudessem relacionar a explicação dos autores com os novos conhecimentos da biologia.

\section{Categoria 5: Biologia do desenvolvimento.}

Nessa categoria o foco foi a biologia evolutiva do desenvolvimento. Procurou-se identificar se o texto continha algo além da visão da embriologia comparada, ou seja, a ideia de que os embriões de grupos aparentados evolutivamente têm desenvolvimento semelhante.

\section{Categoria 6: Plasticidade.}

Assim como na categoria anterior, buscamos em todos os capítulos destinados à evolução, referências à capacidade de um genótipo determinar fenótipos diferentes, dentro de um contínuo de variação limitado, dependendo do ambiente.

\section{Categoria 7: Epigenética.}

Aqui se buscou identificar ideias que remetessem a herança de modificações reversíveis e herdáveis sem alteração da sequência nucleotídica do DNA.

As categorias 5, 6 e 7 foram construídas a priori, pois representam os assuntos inicialmente buscados nos LD. As outras quatro categorias anteriores surgiram durante a análise, porque essa divisão é uma forma comumente utilizada pelos autores para dividir os conteúdos. Portanto, explorar o texto baseando-se nas sete categorias mostrou-se eficaz para a comparação das diferentes obras.

\section{Resultados e discussão}

Os resultados estão apresentados, de forma resumida, na Tabela 1. Esta mostra a presença/ausência dos conteúdos pesquisados nos diferentes LD, dentro de cada categoria de análise.

Tabela1: presença, indicada por um $X$, de conteúdo em cada categoria de análise nas obras analisadas.

\section{Categorias}

\begin{tabular}{|c|c|c|c|c|c|c|c|}
\hline Livros & $\begin{array}{c}1 . \\
\text { Contextualização } \\
\text { histórica }\end{array}$ & $\begin{array}{c}2 . \\
\text { Darwinismo } \\
\text { e } \\
\text { Lamarckismo }\end{array}$ & $\begin{array}{c}3 . \\
\text { Síntese } \\
\text { Evolutiva } \\
\text { Moderna }\end{array}$ & $\begin{array}{l}\text { 4. Genética } \\
\text { de } \\
\text { populações }\end{array}$ & $\begin{array}{c}\text { 5. Biologia do } \\
\text { desenvolvimento }\end{array}$ & $\begin{array}{c}6 . \\
\text { Plasticidade }\end{array}$ & $\begin{array}{c}7 . \\
\text { Epigenética }\end{array}$ \\
\hline & R. B. E. C. T., vol 8 & , núm. 3, mai-a & go.2015 & ISSN - 1982-8 & $373 x$ & & 73 \\
\hline
\end{tabular}




\begin{tabular}{|c|c|c|c|c|c|c|}
\hline L1 & $x$ & $x$ & $x$ & $x$ & $x$ & $x$ \\
\hline L2 & $x$ & $x$ & $x$ & $x$ & $x$ & \\
\hline L3 & $X$ & $x$ & $x$ & $x$ & $x$ & \\
\hline L4 & $x$ & $x$ & $x$ & $x$ & & \\
\hline L5 & $x$ & $x$ & $x$ & $x$ & & \\
\hline L6 & $x$ & $x$ & $x$ & $x$ & & $x$ \\
\hline
\end{tabular}

Embora todos os livros apresentem as temáticas: contextualização histórica; darwinismo e lamarckismo; Síntese moderna evolutiva; e Genética de populações, a abordagem é muito diferente entre eles. Como o critério de inclusão foi a presença do conteúdo, todos os livros foram classificados apresentando noções destas categorias. Entretanto, há diferenças sensíveis.

Categoria 1.Contextualização histórica:

Na contextualização histórica, há obras que seguem o padrão de apresentação cronológica dos fatos, como por exemplo neste trecho de L5:

"Em 1859, trinta anos depois da morte de Lamarck, o naturalista inglês Charles Robert Darwin expôs em seu livro A origem das espécies suas ideias a respeito do mecanismo de transformação das espécies" (PAULINO, 2005. p. 135.).

Em outras obras, os autores procuram além de apresentar esse retrospecto cronológico, contextualizar essa produção científica:

"Segundo o pensamento predominante até o século XVIII cada espécie teria surgido de maneira independente, permanecendo sempre com as mesmas características. Até o naturalista Lineu, que criou em 1735 o primeiro sistema de classificação biológica, aceitava essa idéia, conhecida como criacionismo ou fixismo. No início do século XIX, a hipótese de uma transformação das espécies passou a ganhar destaque diante de inúmeras evidências, como a existência de fósseis de organismos diferentes dos organismos atuais" (LINHARES, GEWANDSZNAJDER, 2010. p. 420).

"Apesar de tanto o criacionismo quanto o evolucionismo buscarem explicações para a origem dos seres vivos, há uma diferença fundamental entre eles: o criacionismo não é científico, pois invoca o sobrenatural para explicar fenômenos da natureza. O cerne do pensamento científico é basear as 
explicações para os fenômenos naturais em fatos e processos observáveis na própria natureza" (AMABIS, MARTHO, 2010. p. 146).

Ao utilizar uma obra que dá menos importância aos aspectos históricos, o professor deve complementar durante as aulas as explicações apresentadas no texto. Caso contrário, os alunos poderão ter a impressão equivocada de que o conhecimento científico é construído de maneira linear.

Categoria 2. Darwinismo e Lamarckismo:

De maneira geral, todos os livros apresentaram as ideia de Lamarck e Darwin sem nenhum erro conceitual. Apesar disso, obras como L5 imprimem a ideia de que Lamarck estava totalmente errado e Darwin certo:

"O lamarckismo constitui uma ideia destituída de fundamento científico. [...] Embora o lamarckismo seja refutado para explicar o mecanismo evolutivo das espécies, é dotado de relativa importância, principalmente por considerar a adaptação como um processo necessário para o sucesso evolutivo de uma espécie num determinado meio ambiente" (PAULINO, 2005. p. 134).

Em L2 essa ideia está menos explícita, mas o modo pelo qual os autores relacionam o que foi proposto por Lamarck com os conhecimentos atuais, pode levar o aluno a achar que Lamarck foi ingênuo em suas afirmações. Isso pode ocorrer porque a maneira como o texto do LD é escrito não mostra a relação do momento histórico e do pensamento científico europeu do século XIX. A explicação para a não validade da chamada Lei de transmissão dos caracteres adquiridos é:

"[...] um halterofilista desenvolveria seus músculos com exercícios e essa característica passaria para seus filhos. Por tudo que sabemos hoje, apenas uma modificação nos genes (mutação) pode ser transmitida às gerações seguintes, $e$ mesmo assim se esses genes estiverem nas células germinativas. Assim, ao desenvolver seus músculos com exercícios, um halterofilista não altera os genes de seus espermatozoides responsáveis pelo desenvolvimento dos músculos. Por isso seus filhos não terão músculos mais desenvolvidos" (LINHARES, GEWANDSZNAJDER, 2010. p. 421).

Outras obras, entretanto, esclarecem bem as limitações procedimentais e tecnológicas da época e destacam a importância do trabalho de Lamarck. Isso é bem exemplificado pelo trecho a seguir de L4:

"Lamarck nem poderia ter explicado corretamente a transmissão das características hereditárias, pois na época nada se sabia sobre genes, DNA, e os conhecimentos sobre herança biológica eram incipientes. A teoria evolutiva de Lamarck, embora não explicando corretamente como ocorre a evolução, tem

DOI: Em andamento. 
grande valor histórico, pois ele teve o mérito de relacionar muitos exemplos de adaptações, ou seja, características dos seres vivos que estão relacionadas à sua sobrevivência. [...].

Na época, cinquenta anos após a publicação de Lamarck, ainda nada se sabia sobre o DNA, cromossomos, divisão celular e hereditariedade. Darwin, tanto quanto Lamarck, também não conseguiu explicar a origem das variações nem os mecanismos de herança, mas sua interpretação sobre a evolução por seleção natural se mostrou correta até hoje" (MENDONÇA, LAURENCE, 2010. p.223)

Aqui, novamente, o professor tem que estar atento e evitar a visão da ciência feita por personagens de sucesso e, outros, fracassados. É preciso esclarecer aos alunos que o avanço científico depende da superação de concepções, por vezes mais simplistas, construídas anteriormente por conceitos mais abrangentes que expliquem melhor um problema. $A$ atuação de pesquisadores cujas ideias já foram superadas não pode, contudo, ser vista como negativa. É o trabalho muitas vezes pioneiro desses pesquisadores que fomenta a discussão e leva à pesquisas e reflexões posteriores. Os alunos têm que estar cientes disso.

Categoria 3. Síntese Evolutiva Moderna:

Nesta categoria o aspecto mais relevante é o enfoque histórico que é dado em todos os LD. A maior parte explica que, atualmente, considera-se a mutação gênica, recombinação gênica e a migração como os fatores evolutivos principais, além da seleção natural. É muito comum, também, os autores considerarem o termo "Neodarwinismo" como sinônimo da Síntese Moderna. Em L5 o autor considera inclusive "mutacionismo" como outro sinônimo. Na obra lemos:

"O neodarwinismo ou mutacionismo, constitui uma ampliação das ideias de Darwin: explica as causas das variações nos seres vivos, ponto que o darwinismo clássico não conseguiu explicar" (PAULINO, 2005. p. 136).

Os autores de L6 também utilizam o termo neodarwinismo como sinônimo de teoria sintética da evolução, dizem que essa é a teoria atual da evolução e que utiliza o "binômio variação/ seleção" (SILVA JUNIOR, SASSON, CALDINI JUNIOR, 2010. p. 216).

Embora o intercâmbio entre neodarwinismo e Síntese Moderna Evolutiva seja comum, esta última designação é mais adequada, pois se refere de fato ao evento de consolidação do pensamento evolutivo que envolveu diversos pesquisadores entre as décadas de 1920 e 1940 . Quanto à "neodarwinismo" Mayr (2005) pondera:

"[...] Romanes (1894) cunhou o termo "neodarwinismo" para esse novo tipo de darwinismo sem a herança de características adquiridas. Alguns historiadores recentes exorbitaram o uso do termo "neodarwinismo", designando com ele o conjunto de teorias que emergiu da síntese evolucionista, mas isso foi um erro. 
Neodarwinismo é a designação para o darwinismo revisado por Weismann (com a exclusão de toda a herança de características adquiridas)" (MAYR, 2005, p. 135).

A respeito do termo "mutacionismo", Futuyma (2009a, p. 24) explica que as teorias mutacionistas foram baseadas nos princípios da genética mendeliana. Além disso, esclarece que o mutacionismo representa a ideia, criada no início do século XX, de que organismos que apresentam variações são chamados de mutantes. À princípio, pesquisadores como Thomas H. Morgan e Richard Goldschmidt imaginaram que o processo de mutação seria suficiente para o surgimento de novas espécies, desqualificando o papel da seleção natural.

Mesmo sem o caráter de oposição que o termo mutação teve nos primeiros anos após sua criação, ele - ou o termo derivado "mutacionismo" - não representa de jeito nenhum um sinônimo de Síntese Evolutiva Moderna, pois refere-se a apenas um dos aspectos envolvidos na unificação do pensamento evolutivo e as leis da herança: a mutação.

A parte conceitual é um pouco mais aprofundada em alguns LD. Os autores de L3, por exemplo, discutem conceitos como princípio do fundador e efeito gargalo:

"A redução de uma população inicial em uma ou mais populações pequenas é chamada efeito gargalo (bottleneck, do inglês), uma forma de deriva genética. A variabilidade genética da ou das populações resultantes desse processo muito provavelmente não será a mesma da população original. [...].

Outro caso particular de deriva genética é o princípio do fundador, que se refere ao estabelecimento de uma nova população à partir de poucos indivíduos que emigram de uma população original. Esses indivíduos serão portadores de pequena fração da variabilidade genética da população de origem. Novos alelos poderão surgir por mutação ou por uma nova onda migratória. Essa pequena população sofrerá os efeitos da seleção natural, podendo dar origem a uma nova espécie" (LOPES, ROSSO, 2010. p. 452).

Portanto, ainda que com diferentes abordagens, todos os LD trazem o conteúdo da Síntese Evolutiva Moderna. Alguns esclarecem mais o contexto histórico e a importância que a síntese moderna teve na consolidação do pensamento evolutivo. É o caso de L3, no qual os autores explicam o fato de no início do século XX ter sido proposto que a mutação era a única responsável pela evolução, como discutido acima.

Categoria 4.Genética de populações:

L3, L5, e L6 trazem a parte de genética de populações em um capítulo diferente daquele em que a Síntese Evolutiva Moderna é discutida. Assim como na categoria anterior, L3 traz um 
aprofundamento dos aspectos conceituais apresentando as ideias gerais da teoria do equilíbrio pontuado:

\begin{abstract}
"Em 1972, dois cientistas americanos, Stephen Jay Gold e Niles Eldredge, propuseram a teoria do equilíbrio pontuado, uma nova maneira de entender a especiação. Eles se perguntavam porque não conseguiam encontrar no registro fóssil as mudanças graduais nos organismos que se sempre se acreditou que ocorressem na evolução. Em vez disso, encontravam súbitas aparições de espécies fósseis (súbitas em termos geológicos, embora fossem lentas na escala de tempo da vida humana), seguidas de longos períodos sem que esses organismos sofressem mudanças" (LOPES, ROSSO, 2010. P. 468).
\end{abstract}

Mesmo com diferentes abordagens, todos os LD trazem explicações sobre genética de populações que permitem aos alunos relacionar os conceitos genéticos aos processos evolutivos e entender que a evolução biológica significa variação nas frequências alélicas. Alguns, entretanto, alcançam maior êxito (L1, L2 e L4), pois abordam a genética de populações em conjunto com a Síntese Evolutiva Moderna, enquanto outros o fazem de maneira separada (L3, L5 e L6).

Categoria 5. Biologia do desenvolvimento:

Entre os livros analisados, três apresentam noções de biologia do desenvolvimento (evodevo): L1, L2 e L3. Entretanto, ao inserir as obras nesta categoria, não estamos considerando que o conceito apresentado refere-se a toda noção de evo-devo. A inserção das obras deve-se às ideias contidas no texto, quando estas se referiam à embriologia comparada:

"Quando se compara a formação embrionária de estruturas com organização anatômica semelhante em diferentes espécies, verifica-se que elas se originam e se desenvolvem de maneira muito parecida. Isso porque é nessa fase do desenvolvimento que se define o plano básico de organização corporal, que os organismos aparentados herdaram de um ancestral comum" (AMABIS, MARTHO, 2010. P. 155, negrito nosso).

"A embriologia comparada permitiu a descoberta de parentesco entre espécies que, quando adultas, são muito diferentes uma das outras. A semelhança do embrião entre essas espécies é explicada porque novos órgãos se desenvolvem de uma organização básica do embrião" (LINHARES, GEWANDSZNAJDER, 2010. P. 429. Negrito nosso.).

"O estudo comparado da embriologia de diversos vertebrados mostra a grande semelhança de padrão de desenvolvimento inicial. À medida que o embrião se 
desenvolve, surgem características individualizantes $e$ as semelhanças diminuem" (LOPES, ROSSO, 2010. P. 438. Negrito nosso.).

Conforme exemplificado pelos fragmentos citados acima, o que determinou a consideração de noções de biologia do desenvolvimento é a ideia de organização ou plano básicos dos embriões. Portanto, os três LD contem noções de evo-devo.

Categoria 6.Plasticidade:

Os livros L1 e L6 apresentam noções de plasticidade. Nos dois LD a explicação é ilustrada com o exemplo clássico da pigmentação da pele em humanos. Em L1:

"Outro exemplo de adaptação individual ocorre quando uma pessoa se expõe ao sol. Após alguns dias de exposição à luz solar, a pele fica mais escura em decorrência do aumento na síntese do pigmento melanina. Um fator ambiental, a radiação ultravioleta, põe em ação um mecanismo que intensifica a síntese do pigmento, em um processo comandado pelos genes. Grande parte dos genes é capaz de modificar sua forma de expressão conforme as condições ambientais. Geralmente o genótipo comanda não um único fenótipo, mas uma faixa de possibilidades fenotípicas que se manifestam de acordo com a influência ambiental. A capacidade de um genótipo produzir diferentes fenótipos em resposta ao ambiente é o que se denomina sua norma de reação" (AMABIS, MARTHO, 2010. p. 172. Negrito nosso).

Em L6, o conceito está subentendido, mas o tema é abordado:

"Essas mudanças (que acontecem ao longo do tempo nas espécies) tornam as espécies mais aptas a sobreviver no seu ambiente. [...] Note que não estamos falando de da adaptação de um individuo ao ambiente, e sim, da adaptação da população. Ficarmos bronzeados quando nos expomos ao Sol é um exemplo de adaptação individual. Isso não tem nenhuma relação com a adaptação evolutiva, que é muito lenta e torna as populações mais 'encaixadas', ajustadas em seu ambiente com o passar do tempo" (SILVA JUNIOR, SASSON, CALDINI JUNIOR, 2010. p. 202. Negrito nosso).

Consideramos para a inclusão na categoria, portanto, o fato dos autores tratarem da variação que um fenótipo pode ter, dentro da determinação do genótipo.

Categoria 7.Epigenética:

Nenhum dos livros apresentou qualquer conteúdo relacionado à herança epigenética.

\section{Considerações finais}

R. B. E. C. T., vol 8, núm. 3, mai-ago.2015 ISSN - 1982-873X

DOI: Em andamento. 
Os livros didáticos têm expressiva importância nos processos de ensino-aprendizagem, não só de evolução biológica, mas da biologia como um todo. E esse foi o motivo que nos levou a elaborar essa análise de aspectos do conteúdo de evolução nos LD.

O desenvolvimento científico é rápido e incessante, gerando consequentemente a necessidade de atualização constante dos materiais didáticos. Com o desenvolvimento recente de áreas contemporâneas das ciências biológicas, novos conhecimentos surgem e ajudam na compreensão do processo evolutivo.

Com a análise apresentada nesse trabalho, pode-se perceber que, embora os livros apresentem algum aspecto evolutivo quando trata dos outros assuntos da biologia, é nos capítulos destinados à evolução biológica que o aluno entra em contato com aspectos da vida e das publicações de Lamarck e Darwin. É também nessa parte dos LD que os autores explicam de maneira mais aprofundada os mecanismos evolutivos. Nota-se ainda que nem sempre o texto se preocupa em despertar no aluno a criticidade em relação ao processo de construção do conhecimento científico, chegando inclusive, em alguns casos, a reduzi-lo à uma sequencia de eventos históricos que parecem ser ordenados e sucessivamente progressivos.

As temáticas analisadas nas categorias 1, 2, 3 e 4 estão presentes em todos os livros. $\mathrm{Na}$ categoria 1 - Contextualização histórica ficou evidente as diferentes abordagens históricas apresentadas nos livros. Entretanto, considera-se significativo que dos seis livros analisados, cinco (L1, L2, L3, L4 e L6) já apresentam uma contextualização histórica mais relevante para a compreensão da construção da ciência. Na categoria 2 - Lamarckismo e Darwinismo o que nos chamou atenção foi, ainda que apenas em alguns livros (L2 e L5), a presença das ideias de Lamarck como contrárias às Darwin ou destituídas de fundamento científico. Mesmo diante de toda a pesquisa na área de ensino de ciências, essas proposições ainda estão presentes nos livros.

As categorias 3 - Síntese Evolutiva Moderna e 4 - Genética de populações foram estabelecidas dessa forma porque parte dos próprios LD trazem essa separação. Entretanto, consideramos que um ponto a ser discutido é a separação histórica e conceitual das temáticas da Síntese Evolutiva Moderna. Em alguns livros os autores chegam a separar em capítulos diferentes (L3, L5 e L6). Consideramos este ponto um problema, pois a genética de populações, embora amplamente discutida, acaba sendo apresentada de uma forma atemporal. Em relação à categoria 4 , todos os livros abordam o conteúdo de maneira correta, embora algumas estabeleçam melhor sua relação com o processo evolutivo, como no caso de L1 que além de explicar os efeitos da mutação, da recombinação gênica e da seleção natural, explica o efeito da migração e da deriva gênica, comentando inclusive sobre o efeito do fundador.

Na categoria 5 - Biologia do desenvolvimento constatou-se que já existem relações com os padrões de desenvolvimento dos organismos. Invariavelmente essas relações aparecem no momento em que os autores discutem a embriologia comparada. Ainda sim, o que diferencia as 
obras incluídas nesta categoria é a presença do conceito de padrão de desenvolvimento. $\mathrm{Na}$ Categoria 6 - Plasticidade, mesmo usando um exemplo clássico (pigmentação da pele), as duas obras incluídas nessa categoria mostram que um genótipo não determina um fenótipo invariável, mas sim, um fenótipo possível dentro de limites de variação da determinação genotípica (norma de reação). Mesmo não sendo diretamente abordado nas categorias 5 e 6 (como um subitem do capítulo, por exemplo) os textos dos LD possibilitam uma ideia desses fenômenos no processo evolutivo, permitindo ao professor um ponto de discussão a respeito destas temáticas.

Embora a categoria 7 - Epigenética não esteja contemplada em nenhum LD, há atualmente assuntos que possibilitariam a introdução desse tema nos LD. Como por exemplo, a ação de príons na conhecida encefalopatia enpongiforme bovina - BSE (doença da vaca louca), muito comentada na mídia ultimamente.

Pela análise, vimos que esses conteúdos não estão muitos presentes nos livros didáticos, pelo menos de maneira direta. Um fator a ser considerado é o fato de serem temas recentes na área, e por isso, ainda não terem sido incorporados na elaboração dos livros didáticos. Contudo, a importância desses conhecimentos torna interessante buscá-los nos LD, principal material utilizado na educação básica. Novas pesquisas relacionadas tanto ao ensino de evolução, quanto à inserção de conhecimentos recentemente descoberto são necessárias para uma visão mais profunda do tema, e para que se possam propor ações que incrementem o ensino de evolução biológica na educação básica.

\section{Referências bibliográficas}

BARDIN, L. Análise de conteúdo. Lisboa: Edições 70, 1977.

BIZZO, N. EL-HANI, C. N. O arranjo curricular do ensino de evolução e as relações entre os trabalhos de Charles Darwin e Gregor Mendel. Filosofia e História da Biologia. V. 4, p. 235-257, 2009.

BIZZO, N. PELLEGRINI, G. Os jovens e a Ciência. 1a ed. Curitiba, PR: CRV, 2013. 154 p.

BOGDAN, R. C. \& BIKLEN, S. K. Investigação Qualitativa em Educação: uma introdução à teoria e aos métodos. 2006. 336 pp. Porto: Porto Editora.

BRASIL. Secretaria de Educação Básica. Orientações curriculares para o ensino médio: ciências da natureza, matemática e suas tecnologias. Brasília: Ministério da Educação/ MEC, 2006. v. 2. 137 p.

BRASIL. Secretaria de Educação Básica. Parâmetros Curriculares Nacionais: parte III - ciências da natureza, matemática e suas tecnologias. Brasília: Ministério da Educação/ MEC, 2000. 58 p.

BRASIL. Secretaria de Educação Básica. PCN+: ciências da natureza, matemática e suas tecnologias (Orientações educacionais complementares aos parâmetros curriculares nacionais). Brasília: Ministério da Educação/ MEC, 2002. 144 p.

R. B. E. C. T., vol 8, núm. 3, mai-ago.2015 ISSN - 1982-873X

DOI: Em andamento. 
CARROLL, S. B. Infinitas formas de grande beleza: Como a evolução forjou a grande quantidade de criaturas que habitam o nosso planeta. Rio de Janeiro: Jorge Zahar, 2006. 303 p.

DALAPICOLLA, J. SILVA, V. A. GARCIA, J. F. M. O uso da evolução como eixo integrador da biologia em livros didáticos do ensino médio In.: VIII Encontro Nacional de Pesquisa em Ciência. 8, 2011, Campinas. Anais... Campinas: SBFHiB, 2011.

DOBZHANSKY, T. Nothing in Biology makes sense except in the light of evolution. The American Biology Teacher, Vol. 35, p. 125-129. 1973.

FUTUYMA, D. J. (Ed.). Evolução, ciência e sociedade. Ribeirão Preto: Sociedade Brasileira de Genética, 2002. 73 p. . Biologia evolutiva. 3. ed. Ribeirão Preto: Funpec, 2009. 830 p. . Evolution. Massachusetts: Sinauer Associates, 2009. 633 p.

GOEDERT, L. DELIZOICOV, N. C. ROSA, V. L. Formação de professores de biologia e a prática docente - o ensino de evolução. In.: IV Encontro Nacional de Pesquisa em Ciência. 4, 2003, Bauru. Anais... Bauru: SBFHiB, 2003.

LEWIN, B. GENES IX. Massachusetts: Jones and Bartlett Publishers, 2009, 892p.

MAYR, E. Biologia, ciência única: reflexões sobre a autonomia de uma disciplina científica. São Paulo: Companhia das letras, 2005. 266 p.

MULLER, G. B. Epigenetic innovation. In: PIGLIUCCI, M.; MULLER, G. B. Evolution - the extended synthesis. Cambridge: MIT Press, 2010. p. $307-332$.

OLIVEIRA, T. B.; SILVA, C. S. F., ZANETTI, J. C. Pesquisas em Ensino de Genética (2004-2010). In.: VIII Encontro Nacional de Pesquisa em Ciência. 8, 2011, Campinas. Anais... Campinas: SBFHiB, 2011.

PIGLIUCCI, M. An extended Synthesis for Evolutionary Biology. The Year in Evolutionary Biology 2009: Ann. N.Y. Acad. Sci. 1168: 218-228 (2009).

RIDLEY, M. Evolução. 3. ed. Porto Alegre: Artmed, 2006. 752 p.

TIDON, R. LEWONTIN, R. C. Teaching evolutionary biology. Genetics and Molecular Biology. São Paulo. v. 27, n. 1, p. 124-131. 2004.

TIDON, R. VIEIRA, E. O ensino da evolução biológica: um desafio para o século XXI. Com Ciência. Campinas, n. 107. 2009. 
Francisco Paulo Caires Junior - Bacharel e Licenciado em Ciências Biológicas pela Universidade Estadual de Londrina - UEL. Mestrando do Programa de Pós-Graduação em Ensino de Ciências e Educação Matemática (PECEM - UEL). E-mail: caires88@hotmail.com

Mariana Aparecida Bologna Soares de Andrade - Doutora em Educação para a Ciência (UNESPBAURU). Professora do Departamento de Biologia Geral e do Programa de Pós-Graduação em Ensino de Ciências e Educação Matemática (PECEM- UEL) da Universidade Estadual de LondrinaUEL. E-mail: mariana.bologna@gmail.com 